\title{
GAS TURBINE AERODYNAMICS IMPROVEMENT VIA A DESIGN OF INTELLIGENT FRACTIONAL CONTROL
}

\author{
DEBBAH Abdesselam ${ }^{1 *}$, KHERFANE Hamid ${ }^{2}$, KELAIAIA Ridha ${ }^{3}$ \\ ${ }^{1}$ L2RCS Laboratory, Université Badji Mokhtar, Annaba, Algeria, \\ Department of Petro-chemical, Université 20 août 1955-Skikda, PB $N^{\circ} 26$ Route Elhadaik, Skikda 21000, \\ Algeria,e-mail: a.debbah@univ-skikda.dz \\ ${ }^{2}$ L2RCS Laboratory, Université Badji Mokhtar, Annaba, Algeria \\ e-mail: hamid_kherfane@yahoo.fr \\ ${ }^{3}$ LGMM Laboratory, Université 20 août 1955-Skikda, PB No 26 Route Elhadaik, Skikda 21000, Algeria \\ e-mail: r.kelaiaia@univ-skikda.dz.
}

\begin{abstract}
Gas turbines are complex processes characterized by the instability and uncertainty of various sources. The range of useful operating in an axial compressor which is part of a turbine gas is limited by aerodynamic instabilities that are surge and rotating stall. This paper presents two intelligent fractional order sliding mode controllers. At first, a robust sliding fractional surface form is proposed to deal with hazardous phenomena which limit compression systems performance, and speed transitions, which can lead to temporary stall development, pressure drop at the output, degrade the effective operation of compressors and consequently gas turbines. Second, to reduce the chattering/fluctuation in control, a fuzzy logic and finite time criterion are used as switching control at the reaching phase in the sliding mode control. Additionally, the controller gains are obtained by offline multi-objective Particle swarm optimization (MOPSO) search. Finally, the surge and rotating stall of a Variable Speed Axial Compressor (VSAC) in a gas turbine are investigated under the system nonlinearities and also in presence of an external disturbance and perturbations. The simulation results signify the performance of the two MOPSO-based fractional sliding mode controllers.
\end{abstract}

KEYWORDS: Gas turbine, axial compressor, surge, rotating stall, Fractional order sliding mode control (FOSMC), Multi-objectives Particle Swarm optimization (MOPSO).

\section{Introduction}

The development experienced by civil or military aviation, the growth of the industry processes as well as the field of the generation of one energy are related to the development an essential element which is the gas turbine. The latter is a machine that produces mechanical energy and high velocity exhaust gases and high temperature. The mechanical energy is used to drive a compressor, fan, etc. The gas turbine is however subject to nonlinear phenomena of different nature: aerodynamic (pumping and rotating stall), aero-elasticity (the float) and combustion that do not allow proper operation [1]. In this work, we will focus on the aerodynamic non-linearities. Gas turbines suffer from two types of aerodynamics instabilities which limit their efficiency and performance: rotating stall and surge. These phenomena are closely related. Rotating stall is a non-axisymmetric perturbation that travels around the annulus of the compressor while surge is a large axial oscillation of the flow [1]. The low order model of Moore and Greitzer for the post stall transients of axial compression systems has been used extensively in stall/surge analysis and control. In the original work of Moore and Greitzer, the compressor speed is assumed constant. If the equilibrium of the compression systems is located to the left of the surge line which passes through the local maxima of the compressor characteristic, the flow becomes unstable. Dependent on certain 
system parameters and as be demonstrated in [2], the compressor speed, the instability can take the form of rotating stall, surge or both. This model has been successfully applied to a wide variety of stability and control problems. Moore and Greitzer model has the following advantages: it captures most nonlinear and operational effects. It is low order and physical rather than computational [3]. In 1997, Gravdahl and Egeland [1] derived a similar model and investigated surge and speed control. However, these models were both developed for centrifugal machines and did not include rotating stall as a state. For the first time, the model developed by Gravdahl for axial compressors considered the B-parameter (proportional to the speed of the compressor) as a state and included higher harmonics of rotating stall as well [3].

This new high order extension of Moore-Greitzer model not only shows the previous qualitative behavior such as surge and stall development but also introduces some novel phenomena as a direct consequence of adding the new state to the model. These phenomena can exclusively be described by the non-constant speed model [1]. Gravdahl [3] initially demonstrated the temporary development of rotating stall at an operating point far from surge line because of speed variations. Model simulations showed that amplitudes of rotating stall harmonics temporarily increase while the machine is accelerating, but are quickly damped out as desired speed is reached [4]. Output pressure also drops during speed transitions. Contrary to Gravdahl's non-constant speed model, Moore-Greitzer original model does not imply any rotating stall development, since the working point is situated by an adequate margin to surge line. This temporary stall development and pressure drop can cause trouble for the normal operation of turbo-machines [4]. Furthermore, including model uncertainties (the precise estimation of model parameters, especially in the unstable zone, being difficult) and external perturbations make the problem even more challenging [10].

The aim and the motivation of this work comes from the fact that to properly use the compressor sizing, it must be operated at its effective point which is unstable point [2],[5],[12],[14], taking into account its variable speed nature [6-9],[10-13],[15-16], the mathematical complication of the Gravdahl-Egeland model, prior knowledge of the actual operating conditions, and the limits and actuator dynamics.

The contribution of this paper is to satisfy this nonlinear control problem, by finding a suitable combination between the robustness of the fractional order sliding mode controller (FOSMC), and the flexibility of Pareto multi-objective particle swarm optimization (MOPSO) to ensure the robustness, best performances and good behavior of the actuators without the need to prior knowledge about dynamic of system, and/or uncertainties bounds, making the proposed controllers satisfactory for real applications. The performance of the resultant control law can be systematically achieved but at the expense of chattering and fluctuation effect. This may damage the mechanical components of the system, especially the actuators. To suppress this unwanted effect two techniques have been investigated in this paper. The first technique is using a fuzzy logic control to replace the discontinuous signum function, and the second technique is the optimization of a novel control criterion. Parameters of fractional order surface and fuzzy controller gains are obtained by offline Multi-objective Particle Swarm Optimization (MOPSO) search based on Finite Time Criterion (FTC), this distinguishes it from existing fractional order sliding mode controllers in literature [17-21]. The present paper is organized as follows. The modelling of gas turbine aerodynamics is presented in section 2. Then, the Control design is given in Section 3. The optimization design is illustrated in Section 4. Afterwards, simulation results for the designed controllers are presented in Section 5. Finally, concluding remarks are presented in the last section. 


\section{Modelling of gas turbine aerodynamics}

The compression process studied in this paper comprises an intake duct, inlet guide vanes IGV, variable speed axial compressor, the exit duct, plenum volume (turbine), varying area throttle valve, varying area close-coupled valve (Fig.1). Throttle can be viewed as a streamlined model of a turbine [2].
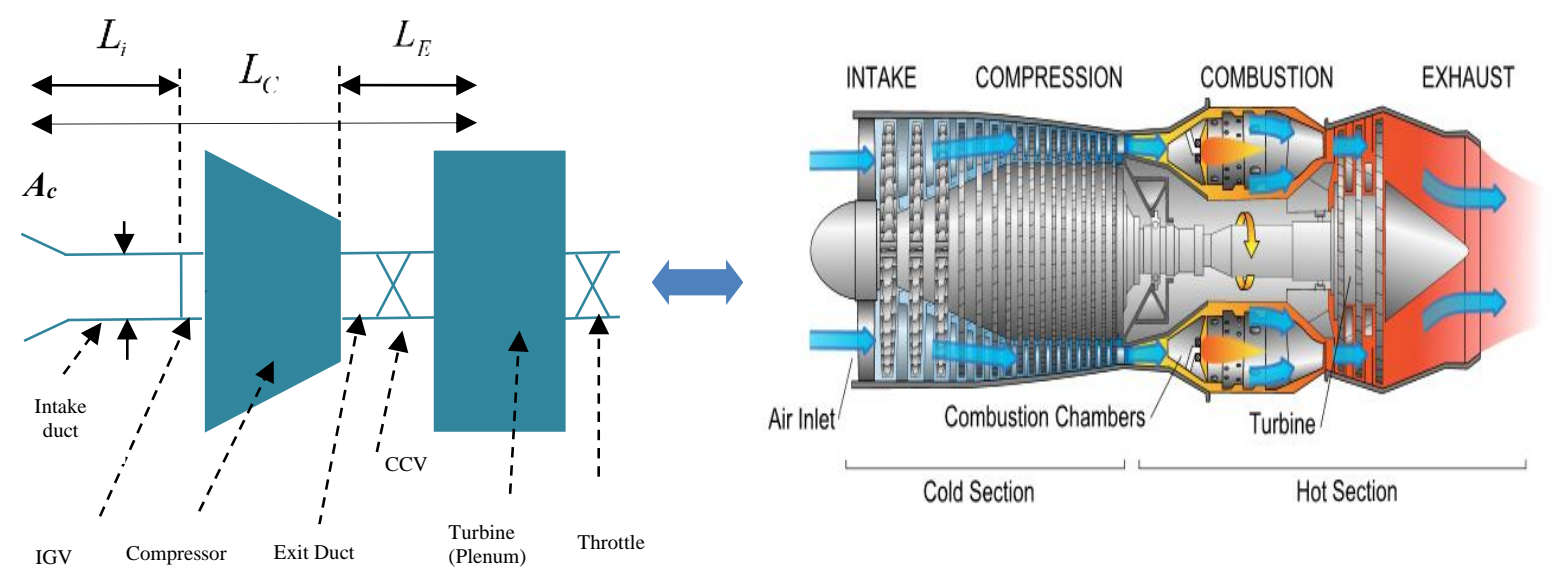

Fig. 1 Schematic of system showing non dimension lengths in gas turbine [2]

Gravdahl developed a model for compressor, the exit duct, plenum volume (turbine), varying area throttle valve, and varying area close-coupled valve (Fig.1). Throttle can be viewed as a streamlined model of a turbine [2]. Gravdahl developed a model for variables peed axial compressors and considered the speed of the rotor as a state variable [2]. Later, Zaiet et al. [8] modified the model to include the pressure drop over a CCV and to make it suitable for control applications. The states $\phi, \psi$ and $U$ denote respectively the annulus averaged mass flow coefficient, the non-dimensional plenum pressure, and the speed of the rotor $(\mathrm{m} / \mathrm{s}) . \zeta$ is a non-dimensional time, $J_{1}$ is the squared amplitude of the first harmonic of rotating stall [5]. The actuators forces are input variables $u_{1}, u_{2}$ and $u_{3}$ defined respectively as: the pressure drop over $\mathrm{CCV}$, the throttle gain, and the non-dimensional drive torque being used to increase the speed. At an operating point $\left(\Phi_{0}=0.5, \Psi_{0}=0.66, U_{0}=9.617\right)$, the dynamic model can be given in the form of state-space equations (see [1],[2] for more details). The model which only includes the first harmonic of rotating stall and comprises actuator forces is given in the following equations:

$$
\begin{gathered}
\frac{d \phi(\zeta)}{d \zeta}=\frac{H}{l_{c}(\zeta)}\left[-\frac{\psi(\zeta)+\psi_{c 0}}{H}+1+\frac{3}{2}\left(\frac{\phi(\zeta)}{W}-1\right)\left(1-\frac{J_{1}(\zeta)}{2}\right)-\frac{1}{2}\left(\frac{\phi(\zeta)}{W}-1\right)^{3}-\frac{u_{1}(\zeta)}{H}-C_{1} J_{1}(\zeta)-G_{1}\left(\phi(\zeta)_{0}\right) u_{3}+G_{1} c(\phi(\zeta))^{3}+\Delta_{\psi}(\zeta)\right] \\
\frac{d J_{1}(\zeta)}{d \zeta}=J_{1}(\zeta)\left[1-\left(\frac{\phi(\zeta)}{W}-1\right)^{2}-\frac{J_{1}(\zeta)}{4}-G_{2}-G_{3} u_{3}(\zeta)+G_{3} c\left(\phi(\zeta)+\Phi_{0}\right)^{2}-\frac{1}{\gamma_{v}^{2}} C_{2}\left(\phi(\zeta)+\Phi_{0}\right)\right] \frac{3 a H}{\left(1-m_{U}(\zeta) a\right) W} \\
\frac{d \psi(\zeta)}{d \zeta}=\frac{\Lambda_{2}}{U(\zeta)}\left(\phi(\zeta)-u_{2}(\zeta) \sqrt{\psi(\zeta)}\right)-2 \Lambda_{1} \frac{U(\zeta)}{b}(\psi(\zeta)) u_{3}(\zeta)+2 \Lambda_{1} \frac{U(\zeta)}{b}(\psi(\zeta)) c(\phi(\zeta))^{2}-\Delta_{\phi}(\zeta) \\
\frac{d U(\zeta)}{d \zeta}=\Lambda_{1}(U(\zeta))^{2} u_{3}(\zeta)-\Lambda_{1}(U(\zeta))^{2} c(\phi(\zeta))^{2}
\end{gathered}
$$

With $l_{c}(\zeta)=l_{i}+l_{E} \frac{U_{d}}{U(\zeta)}+\frac{1}{a}, m_{u}(\zeta)=(1-m) \frac{U_{d}}{U(\zeta)}-1, C_{1}=\frac{W^{2}}{2 H \gamma_{v}^{2}}, C_{2}=\frac{4 W}{3 H}, G_{1}=\frac{U_{0} \Lambda_{1} l_{E}}{b H}$,

$$
G_{2}=\frac{\mu W}{3 a H}, G_{3}=\frac{2 U_{0} \Lambda_{1}(m-1) W}{3 H b}
$$


The definition of the remaining model parameters $\mathrm{H}, \mathrm{W}, \psi_{c 0}, \gamma_{v}, \Lambda_{1}, \Lambda_{2}, \mathrm{~m}, \mathrm{~b}, \mu, \mathrm{a}$, $\rho_{1} \cong \frac{1}{l_{c}(\zeta)}, \rho_{2} \cong \frac{3 a H}{\left(1-m_{U}(\zeta) a\right) W}$ which are all positive non-zero parameters, can be found in [4][5]. To investigate the effect of uncertainties, we introduce $\Delta \Psi$ and $\Delta \Phi$ in the model.

\section{Control design}

In this section, the aim will be the design of a robust fractional order sliding mode controller to deal with hazardous phenomena which limit compression systems performance, and speed transitions, and especially using fuzzy approach to attenuate the possible chattering and fluctuation in control signal if compared with the SMC.

\subsection{Control of Surge and Rotating Stall with variable speed behaviour}

Let us consider the model $(1,2,3,4)$ as a square MIMO nonlinear affine uncertain system:

$$
\sum_{1}: \dot{x}=f(x)+\sum_{i=1}^{3} g_{i}(x) u_{i}
$$

where the state variable $x=(\phi, J, \psi, U)$ belongs to $R^{4}$ and the control input $u=\left(u_{1}, u_{2}, u_{3}\right) \in R^{3}$. Here, $f(x)$ and $g(x)$ are uncertain smooth functions and $y=(\phi, \psi, U) \in R^{3}$ is a smooth measurable output vector. $\Sigma 1$ is defined in error coordinates and in the regulation problem; the objective is to make the outputs vanish in finite time. Let us define outputs for system $\Sigma 1$ as follows:

$$
\sum_{2}: x_{1,2,3}=\left[x_{1}, x_{2}, x_{3}\right]=[\phi, \psi, U]
$$

Where $\phi=\Phi-\Phi_{0}, \psi=\Psi-\Psi_{0}$ with $\Phi_{0}$ and $\Psi_{0}$ is the efficient Operating Point at the peak of the compressor map. Here, the first time derivative of sliding variables yields:

$$
\sum_{3}:\left[\dot{x}_{1}, \dot{x}_{2}, \dot{x}_{3}\right]^{T}=A(x)+B(x) u
$$

Vector $A(x)$ and matrix $B(x)$ can be partitioned into nominal and unknown parts as follows [5][17]:

$$
\left\{\begin{array}{l}
A(x)=\bar{A}(x)+\Delta_{A}(x) \\
B(x)=\bar{B}(x)+\Delta_{B}(x)
\end{array}\right.
$$

Nominal parts $\bar{A}(x)$, and $\bar{B}(x)$ are known a priori. $\Delta_{A}$ and $\Delta_{B}$ traditionally comprise the model uncertainties and perturbations. In this work, however we consider all terms comprising $J_{1}$ in $\Delta_{A}$. Although $J_{1}$ is a model state variable, it cannot be measured, moreover its nature as a perturbation conveys the idea that it can be thought of as uncertain terms. This approach simplifies the control design and makes the proposed control method applicable.

Assumption 1: $\Delta_{A}$ is polynomial functions of uncertainties, disturbances and $J_{1}$. Due to the boundedness of $\phi$ and $J_{1}$,We assume that there is an a priori known constant $\rho$ such boundedness of $\Delta_{A}$ is ensured $\left|\Delta_{A}\right| \leq \rho$.

Assumption 2: We assume that matrix $\bar{B}(x)$ is non-singular and the associated zero dynamics of $\sum 2$ are asymptotically stable. For the applied model, $\Delta_{B}(x)$ ends up being equal to zero. Assume that Assumptions 1-2 are fulfilled. 
Sliding surface is chosen as [21]:

$$
S_{a, i}=\sigma_{i}+S_{a u x, i}=\left(x_{i}-x_{r e f, i}\right)+\int \beta_{i}\left(x_{i}-x_{r e f}\right) d \zeta
$$

where $\beta_{i}$ is a positive constant and subscript ref stand for reference value. The following Lyapunov function candidate has to be positive definite and its derivative has to be at least negative semi-definite.

$$
V=\frac{1}{2} S_{a, i}{ }^{2} \quad \dot{V}=\dot{S}_{a, i} S_{a, i}
$$

To stabilize uncertain system of equation (8), at first, we define an augmented sliding variable $S_{a, i} \in R^{3}$ as follows:

$$
\dot{S}_{a, i}=\dot{\sigma}_{i}+\beta_{i} \sigma_{i}=\left(\dot{x}_{i}-\dot{x}_{r e f, i}\right)+\beta_{i}\left(x_{i}-x_{r e f, i}\right)=0
$$

Using equations (9)-(12), the control law for the limit case that is; equivalent control $u_{e q}$ is obtained as below:

$$
u_{e q}=\bar{B}^{-1}\left[-\bar{A}+\dot{x}_{r e f, i}-\beta_{i} \sigma_{i}\right] \quad i=1,3
$$

Let the total control signal is chosen to be [5],[17]:

$$
u_{i}=\bar{B}^{-1}\left[-\bar{A}+\dot{x}_{r e f, i}-\beta_{i} \sigma_{i}-\alpha_{i} \operatorname{sign}\left(\sigma_{i}+\int \beta_{i} \sigma_{i} d \zeta\right)\right]=\bar{B}^{-1}\left[-A^{-1}+w\right] \quad i=1,3
$$

where $w=w_{i, n o m}+w_{i, s l i d}, w_{i, n o m}$ with is the auxiliary control input, one can partially decouple the nominal system (the system without uncertainties).

The terms $w_{i, n o m}=-\beta_{i} \sigma_{i}$ are introduced to stabilize the nominal part of system $\Delta_{A}=0$. Now, it can be seen that the discontinuous control law defined below, can ensure the sliding mode on $\left(S_{a, i}=0\right)$ and consequently on $S$ in spite of uncertainties.

$$
w_{i, s i d}(\sigma)=-\alpha_{i} \operatorname{sign}\left(\sigma_{i}+\int-w_{i, n o m} d \zeta\right)
$$

The control law stabilizing the nominal system and rejecting the uncertainties of the model takes the final form

$$
u_{i}=\bar{B}^{-1}\left[-\bar{A}+\dot{x}_{r e f, i}-\beta_{i} \sigma_{i}-\alpha_{i} \operatorname{sign}\left(\sigma_{i}+\int \beta_{i} \sigma_{i} d \zeta\right)\right] \quad i=1,3
$$

$\alpha_{i}$ is a positive switching gain. For proof, see [17]. Then the derivative of the Lyapunov function becomes:

$$
\dot{V}=S_{a, i} \dot{S}_{a, i} \leq-\left|S_{a, i}\right|\left(\alpha_{i}-\rho\right)
$$

If $\alpha_{i}$ is chosen to be $\alpha_{i}>\rho$, then derivative of the Lyapunov function is negative definite $\dot{V}<0$, therefore the system is forced to reach the sliding surface [18],[22-23]. When the control law is chosen as (16), chattering phenomena will occur as soon as the state hits the sliding surface because of discontinuity in signum function. To reduce the chattering a saturation function is used instead of the signum function. Hence, the alternative robust sliding mode control (called RSMC):

$$
u_{i}=\bar{B}^{-1}\left[-\bar{A}+\dot{x}_{r e f, i}-\beta_{i} \sigma_{i}-\alpha_{i} \operatorname{sat}\left(S_{a, i}\right)\right] i=1,3
$$


where

$$
\operatorname{sat}\left(\theta_{i}\right)= \begin{cases}\operatorname{sign}\left(\theta_{i}\right) & \text { if }\left|\theta_{i}\right| \geq \varepsilon_{i} \\ \theta_{i} & \text { if }\left|\theta_{i}\right|<\varepsilon_{i}\end{cases}
$$

$\varepsilon_{i}$ is positive selected variable [18], [22], [23].

\subsection{Fractional-order sliding mode control}

In order to design the proposed controller, we use the following definition and lemmas.

Definition: The Riemann-Liouville (RL) definition of the qth order derivative[24-25]:

$$
{ }_{0} D_{t}^{q} f(t)=\frac{d^{q} f(t)}{d t^{q}}=\frac{1}{\Gamma(m-q)} \frac{d^{n}}{d t^{n}} \int_{0}^{t} \frac{f(t)}{(t-i)^{q+1-n}} d i
$$

where $n-1<q \leq n$ with $\mathrm{n}$ is the integer, $\Gamma($.)is the gama function.

Lemma : The fractional integration operator [24-25]

$$
{ }_{a} I_{t}^{\Xi} f(t)=\frac{1}{\Gamma(\Xi)} \int_{a}^{t} \frac{f(i)}{(t-i)^{1-\Xi}} d i,(t>a ; \Xi \in C ; \operatorname{Re}(\Xi)>0)
$$

is bounded in $L_{p}(\hat{a}, \hat{b}),(1 \leq p \leq \infty,-\infty<\hat{a}<\hat{b}<\infty)$ :

$$
\left\|I_{t}^{\Xi}\right\|_{p} \leq K\|f\|_{p}, \quad\left(K=\frac{(\hat{b}-\hat{a})^{\operatorname{Re}(\Xi)}}{\operatorname{Re}(\Xi)|\Gamma(\Xi)|}\right)
$$

From (10) the following Fractional sliding surface is proposed

$$
\begin{aligned}
& S_{a, i}=\sigma_{i}+\beta_{i} I^{\lambda} \sigma_{i} \\
& \dot{S}_{a, i}=\bar{A}+\Delta A+\bar{B} u_{i}-\dot{x}_{r e f, i}+\beta_{i} D^{1-\lambda} \sigma_{i}
\end{aligned}
$$

As illustrated in [19],[20] and [25], from equation (12) and equation (23), for $\dot{S}_{a, i}=0$, the fractional surface sliding mode control (18) will be:

$$
\left.u_{i}=\bar{B}^{-1}\left[-\bar{A}+\dot{x}_{r e f, i}-\beta_{i} D^{1-\lambda} \sigma_{i}-\alpha_{i} \operatorname{sat}\left(\sigma_{i}+\beta_{i} I^{\lambda} \sigma_{i}\right)\right] \quad i=1,3 \quad \text { With } \lambda \in\right] 0,1[
$$

The saturation function can reduce the chattering, but to have a satisfactory compromise between small chattering and good tracking precision in presence of uncertainties and perturbations, a fuzzy logic control is proposed. Fuzzy fractional order sliding mode controller (FFOSMC) can also be used as in next section [19],[20].

\subsection{Fuzzy Controller}

The saturation function of the control law in (24) is replaced by a fuzzy controller [20]. The combination of fuzzy control strategy with SMC becomes a feasible approach to preserve advantages of these two approaches. The Fuzzy controller comprises three main steps namely, fuzzification, rule evaluation, and defuzzification. The input of the fuzzy controller is the fractional order sliding surface, as well as, the fuzzy system output is switching control 


$$
\begin{aligned}
& \mathrm{R} 1: \text { If } \theta_{i} \text { is NB then } \beta_{\mathrm{i}} \text { is PB } \\
& \mathrm{R} 2: \text { If } \theta_{i} \text { is NM then } \beta_{\mathrm{i}} \text { is PM } \\
& \mathrm{R} 3: \text { If } \theta_{i} \text { is NS then } \beta_{\mathrm{i}} \text { is PS } \\
& \mathrm{R} 4: \text { If } \theta_{i} \text { is ZE then } \beta_{\mathrm{i}} \text { is ZE } \\
& \mathrm{R} 5: \text { If } \theta_{i} \text { is PS then } \beta_{\mathrm{i}} \text { is NS } \\
& \mathrm{R} 6: \text { If } \theta_{i} \text { is PM then } \beta_{\mathrm{i}} \text { is NM } \\
& \mathrm{R} 7: \text { If } \theta_{i} \text { is PB then } \beta_{\mathrm{i}} \text { is NB }
\end{aligned}
$$

In the fuzzification stage, the seven triangular membership functions are given for the inputs and output. Moreover, the IF-THEN rules of fuzzy sliding mode controller are described as [20] ,Where NB:Negative Big. NM: Negative Medium. NS: Negative Small. ZE: Zero. PS: Positive Small. PM: Positive Medium. PB: Positive Big, are the linguistic terms of antecedent fuzzy set.
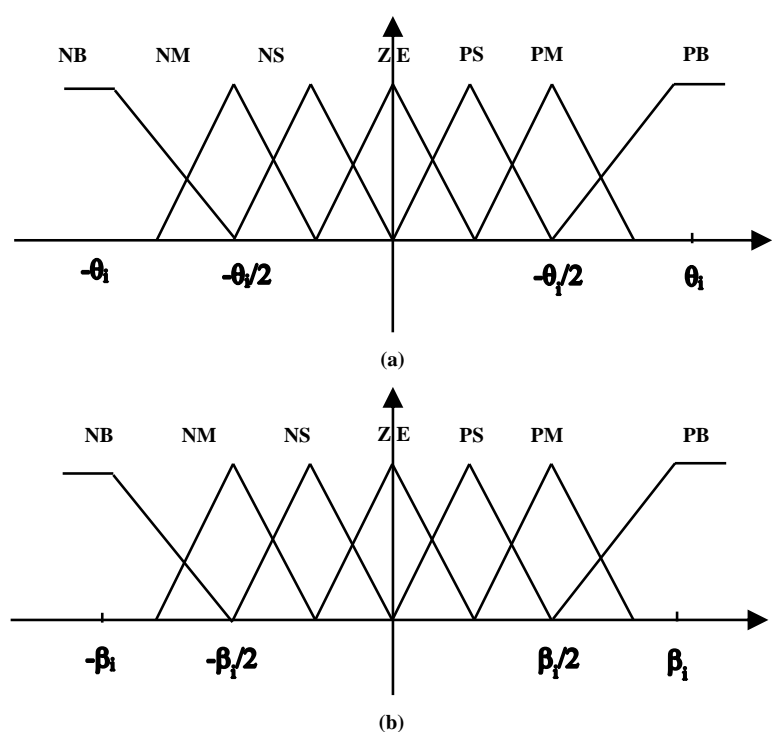

Fig. 2 (a) The input membership functions. (b) The output membership functions.

\section{Design optimization}

The optimization method used in this paper can efficiently choose the appropriate gain parameters for the controllers based on several proposed fitness functions [27-28].

\subsection{The reformulation of the optimisation problem}

The fitness functions are defined in such a way that the selected parameters stand for the most efficient operating point of the optimized fractional controller (called FFOSMC). The finite-time criterion should be used to assess the optimal control. These criteria are defined as follows [19], [26]:

$$
\text { Min } f_{1}\left(\alpha_{i}, \beta_{i}, \lambda_{i}\right)=\int_{0}^{t_{o p}} \zeta \sigma_{i}\left(\alpha_{i}, \beta_{i}, \lambda_{i}\right)^{2} d \zeta, \quad f_{2}\left(\alpha_{i}, \beta_{i}, \lambda_{i}\right)=\int_{0}^{t_{o p}} \zeta u_{i}\left(\alpha_{i}, \beta_{i}, \lambda_{i}\right)^{2} d \zeta
$$

Subjected to $0<\lambda<1, \quad \alpha_{i}>0, \quad u_{2}>0$

The optimization function (27) used in this study can efficiently choose the appropriate gain parameters for attenuate possible chattering/Fluctuation of the controller without using fuzzy design (called OFOSMC): 
Min $f_{l}\left(\alpha_{i}, \beta_{i}, \lambda_{i}\right)=\int_{0}^{t_{\text {pp }}} \zeta \sigma_{i}\left(\alpha_{i}, \beta_{i}, \lambda_{i}\right)^{2} d \zeta, f_{2}\left(\alpha_{i}, \beta_{i}, \lambda_{i}\right)=\int_{0}^{t_{p}} \zeta u_{i}\left(\alpha_{i}, \beta_{i}, \lambda_{i}\right)^{2} d \zeta, f_{3}\left(\alpha_{i}, \beta_{i}, \lambda_{i}\right)=\int_{0}^{t_{\text {pp }}} \zeta \dot{u}_{i}\left(\alpha_{i}, \beta_{i}, \lambda_{i}\right)^{2} d \zeta$

Subjected to $0<\lambda<1, \quad \alpha_{i}>0, \quad u_{2}>0$

Here, $t_{o p}$ is the optimization time, the first fitness function $f_{1}$ stand for tracking performance of the controller. The second fitness function $f_{2}$ stand for minimum control gain. The third one, $f_{3}$, denotes fluctuations/chattering in control signal [18],[19],[26].

\subsection{Multi-objective particle swarm optimisation (MOPSO)}

PSO has simple operation and strong global search ability, so it has been widely used in engineering optimization [29]. Multi-Objective Particle Swarm Optimization (MOPSO) present an exceptionally reduction computational times requirement compared to the other multi-objective optimization, who make it a very promising approach to control problems in which the computational cost is a vital[30]. Additionally, MOPSO was able to cover the full Pareto front of several fitness functions, with respect to some of the best multi-objective evolutionary algorithms known [30-31]. MOPSO is a multi-objective version of PSO which incorporates the Pareto Envelope and grid making technique, similar to Pareto Envelopebased Selection Algorithm to handle the multi-objective optimization problems [30]. Accordingly MOPSO is used to search the parameter space to find appropriate values of the fractional order sliding mode controller (FOSMC) parameters, $\alpha_{i}, \beta_{i}$ for fuzzy sliding mode control, and $\lambda_{i}$ for fractional order sliding surface design.

The modified Velocity and position of each particle can be calculated using the current velocity and distance from $J_{p \text { best }}$ and $J_{g \text { best }}$ use the following equations:

$$
\begin{gathered}
V_{i}^{t+1}=Q V_{i}^{t}+c_{1} \operatorname{rand}_{1}\left(X_{\text {pbest }}-X_{i}^{t}\right)+c_{2} \operatorname{rand}_{2}\left(X_{\text {gbest }}-X_{i}^{t}\right) \\
X_{i}^{t+1}=X_{i}^{t}+\gamma V_{i}^{t+1}
\end{gathered}
$$

Where $c_{1}$ and $c_{2}$ are two positive constants, rand $_{1}$ and rand $_{2}$ are random numbers in the range [0-1], and $Q$ is the inertia weight [32],[33]. Pareto dominance is incorporated into particle swarm optimization (PSO) in order to allow this heuristic to handle problems with several objective functions. Unlike other current proposals to extend PSO to solve multiobjective optimization problems, MOPSO algorithm uses a secondary (i.e., external) repository of particles that is later used by other particles to guide their own flight. A special mutation operator is incorporated to enriching the exploratory capabilities of MOPSO algorithm [30],[34],[35].

\section{The numerical simulation}

In the following time-domain simulations, we simultaneously control the speed and surge/rotating stall which is called closed-loop. The $\bar{A}$ and $\bar{B}$ are the known parts whereas $\Delta A$ and $\Delta B(\Delta B=0)$ which depends on $J$ and perturbations are:

$$
\bar{A}=\left[\begin{array}{c}
\frac{H}{l_{c}(U)}\left[-\frac{\psi+\psi_{c 0}}{H}+1+\frac{3}{2}\left(\frac{\phi}{W}-1\right)-\frac{1}{2}\left(\frac{\phi}{W}-1\right)+G_{1} c(\phi)^{3}\right] \\
\frac{\Lambda_{2}}{U+U_{0}} \phi+2 \Lambda_{1} \frac{U}{b}(\psi) c(\phi)^{2} \\
-\Lambda_{1} U^{2} c \phi^{2}
\end{array}\right] \bar{B}=\left[\begin{array}{ccc}
-\frac{1}{l_{c}(U)} & 0 & \frac{-H G_{1}(\phi)}{l_{c}(U)} \\
0 & \frac{\Lambda_{2}}{U+U_{0}} \sqrt{\psi} & -2 \Lambda_{1} \frac{U}{b} \phi \\
0 & 0 & \Lambda_{1} U^{2}
\end{array}\right] \Delta A=\left[\begin{array}{c}
\frac{-3}{2}\left(\frac{\phi}{W}-1\right)\left(\frac{J_{1}}{2}\right)-C_{1} J_{1}+\Delta \psi \\
-\Delta_{\phi} \\
0
\end{array}\right]
$$




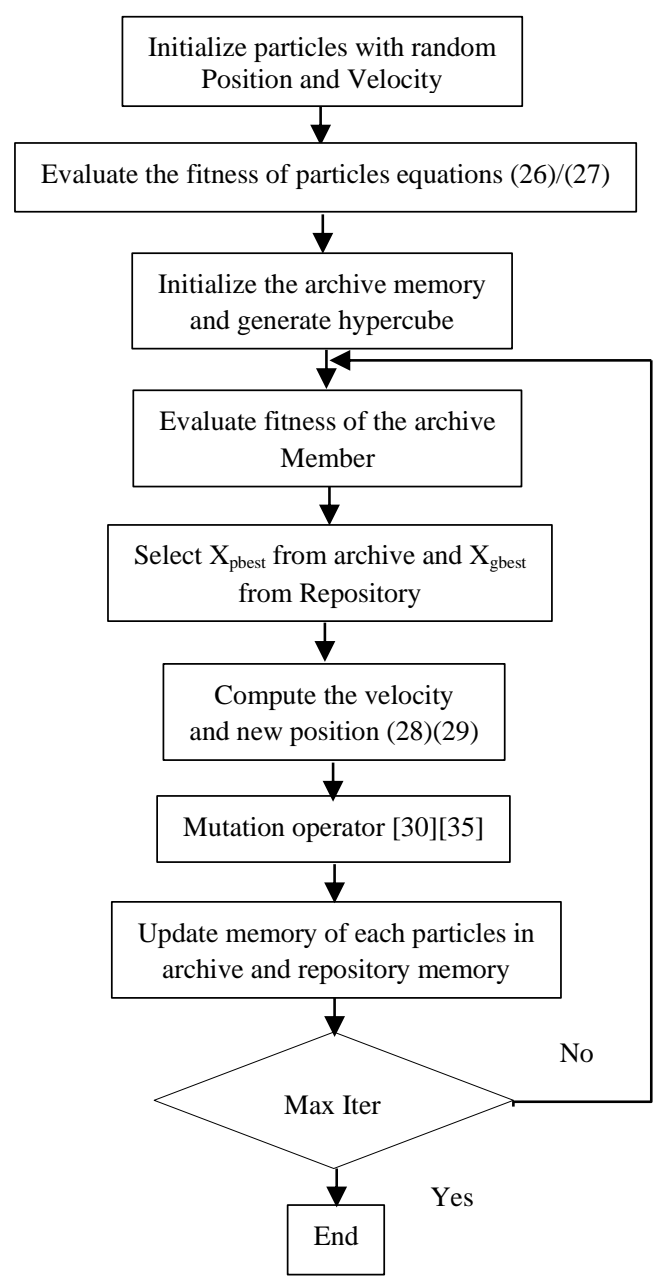

Fig. 3 Flowchart of Multi-objective Particle Swarm Optimization (MOPSO)

To investigate the performance of the two proposed controllers, types of perturbations are applied to the system denoted by $\phi_{d}(\xi), \psi_{d}(\xi)$ are considered as mass flow and pressure disturbances respectively and $d_{\phi}, d_{\psi}$, which represents the uncertainty of compressor map and throttle characteristic. The numerical values of the simulations are given in Table 1.

Table 1. Numerical values used in simulations

\begin{tabular}{|c|c|c|c|c|c|c|c|}
\hline Parameter & Value & Parameter & Value & Parameter & Value & Parameter & Value \\
\hline$W$ & 0.25 & $a$ & 0.3 & $b$ & 96.16 & $d_{\Psi}$ & 0.02 \\
\hline$H$ & 0.18 & $l_{i}$ & 1.75 & $m$ & 1.75 & $\Lambda_{1}$ & $2.168 e-4$ \\
\hline$\mu$ & 0.01 & $d_{\Phi}$ & -0.05 & $l_{E}$ & 3 & $\Lambda_{2}$ & 0.0189 \\
\hline$\rho_{I}$ & $0<\rho_{1}<1$ & $\rho_{2}$ & $0<\rho_{2}<1$ & $c$ & 0.7 & $\gamma_{v}$ & 1 \\
\hline
\end{tabular}

Table 2. PSO Parameters used in simulations [30]

\begin{tabular}{|l|l|l|l|}
\hline Parameters & Value & Parameters & Value \\
\hline $\mathrm{N}^{\mathrm{o}}$ Iterations & 100 & Inertia Q & 0.5 \\
\hline $\mathrm{N}^{\mathrm{o}}$ Particles & 100 & $\mathrm{~N}^{\circ}$ Grids & 30 \\
\hline Dimension & $2 / 3$ & $\begin{array}{l}\text { Repository } \\
\text { Size }\end{array}$ & 250 \\
\hline Value of c1 & 1 & Mutation Rate & 0.1 \\
\hline Value of c2 & 2 & Criterions & $(26) /(27)$ \\
\hline
\end{tabular}


The parameters used for MOPSO performed in the present study are given in Table 2. The Block diagram of the designed controller is shown in Fig. 4. Fig. 5 shows the variables $\phi$ and $\psi$ in the phase space along with equivalent compressor map and stall characteristic. The system start from an effective initial operating point (OP) at the top of the equivalent compressor map (compressor comprising CCV) with $\left(\phi_{0}, \psi_{0}, U_{0}, J_{10}\right)=(0.5,0.66,9.617,0.1)$.

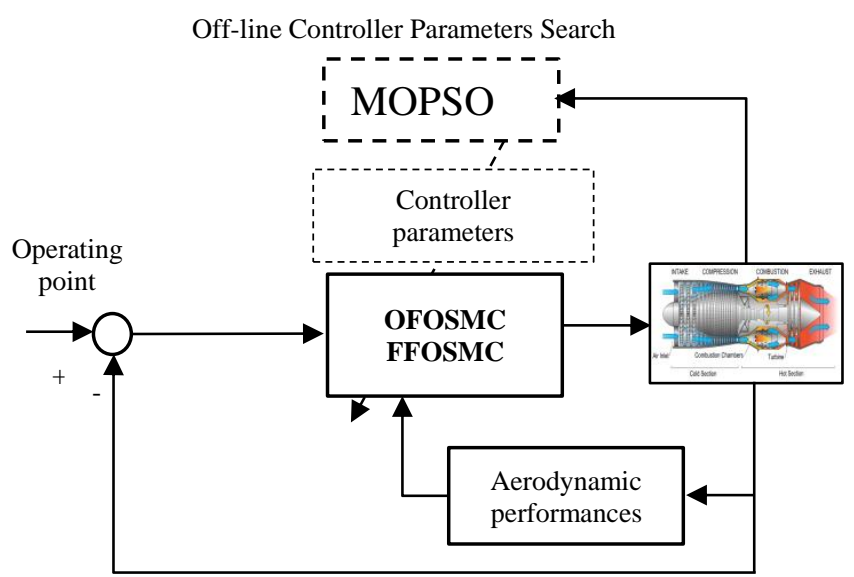

Fig. 4 Block diagram for the controller

Examining of the Fig. 5, we found that the system dynamic in closed loop, stay close to his efficiency operating point $(0.5,0.66)$ despite the existence of uncertainties, perturbation (negligible variation ). As reported in [4], when speed varies at an efficient operating point (e.g. at the peak of the equivalent compressor map), temporary stall developments can lead to a fully developed rotating stall. Here, we will show that the proposed robust nonlinear controller prevents the system from developing such a rotating stall.

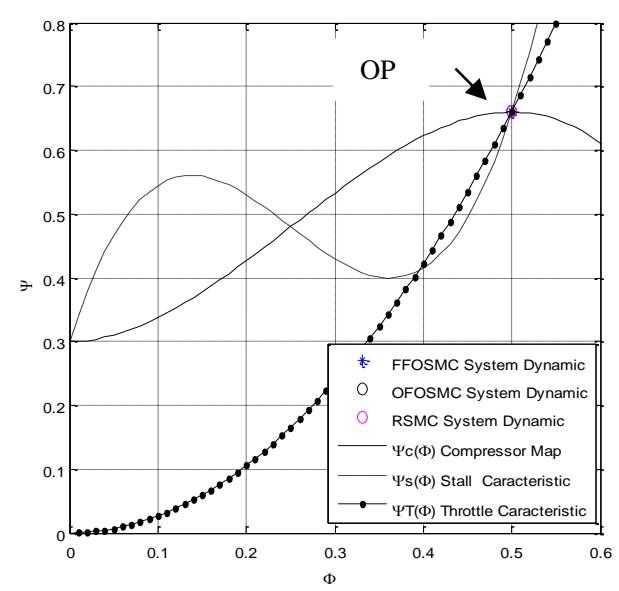

Fig. 5 Closed loop System Map
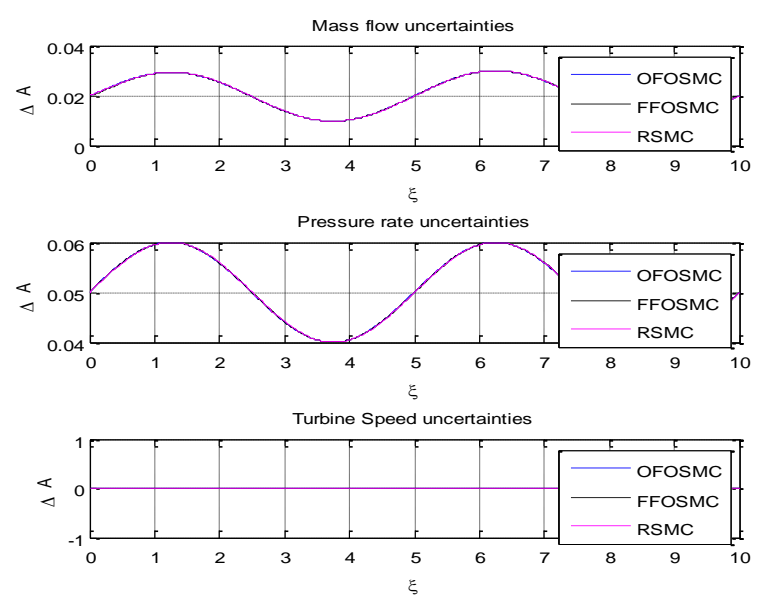

Fig. 6 Flow and Pressure uncertainties

Previously reported results in [4], show that pressure and flow external perturbations can destroy the stability of compressors at an efficient OP and lead to fully developed rotating stall or deep surge depending on the speed of the rotor (i.e. for low speeds the system goes to rotating stall and for high speeds it develops deep surge). Here, we consider the case of high speed operation (according to [2],[4]) and demonstrate that the controller can effectively reject the perturbations and guarantee the stability of the system (Fig.5). Fig.7 shows that on the other hand in closed loop, the controller effectively stabilizes the compression system at 
the efficient OP and prevents it from developing a steady rotating stall due to the speed variation. It immediately damps out rotating stall (Fig. 9) and manipulate the throttle valve.

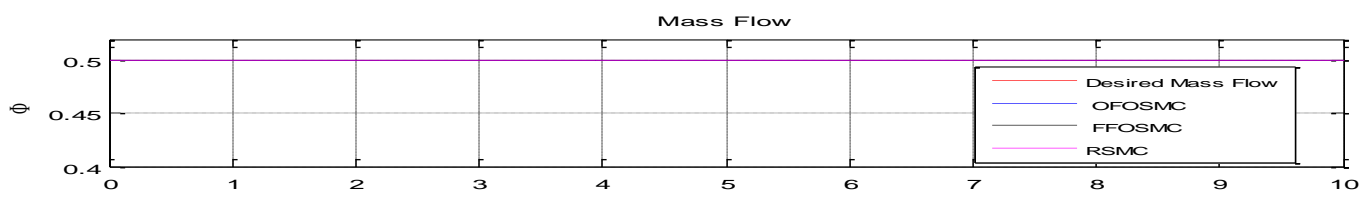

$\stackrel{\xi}{5}$ Rise

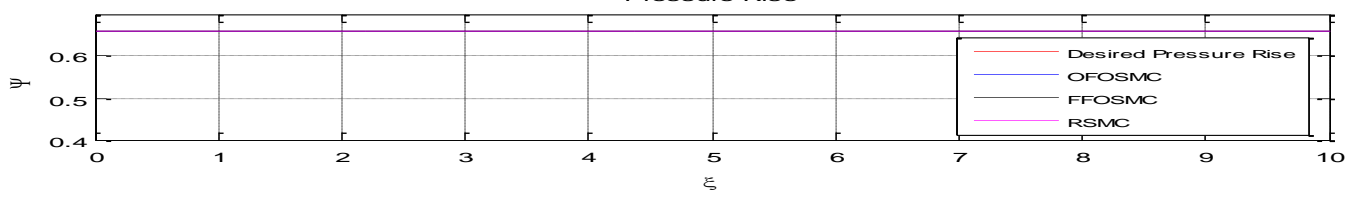

Turbine Speed

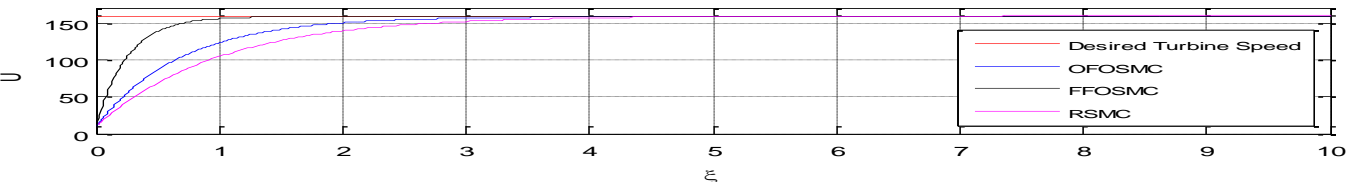

Fig. 7 System Dynamic in Closed Loop

Consequently, we note a variation in throttle actuator (Fig.8), despite that the system still close in his efficient OP, where the pressure is high enough for normal operation of the gas turbine. Results in Fig.8 demonstrate that the two optimized controllers reduce the high frequency behavior of actuators due to the frequency of the perturbation as reported in [14] and [15]. These are even achieved by a smoother control signals. Also, it is worth noting that chattering is attenuated with the designed optimization functions. Additionally, it is seen that the FFOSMC needs much more control turbine torque than the OFOSMC. From the view point of real time applications, the behavior of the controllers is very acceptable.
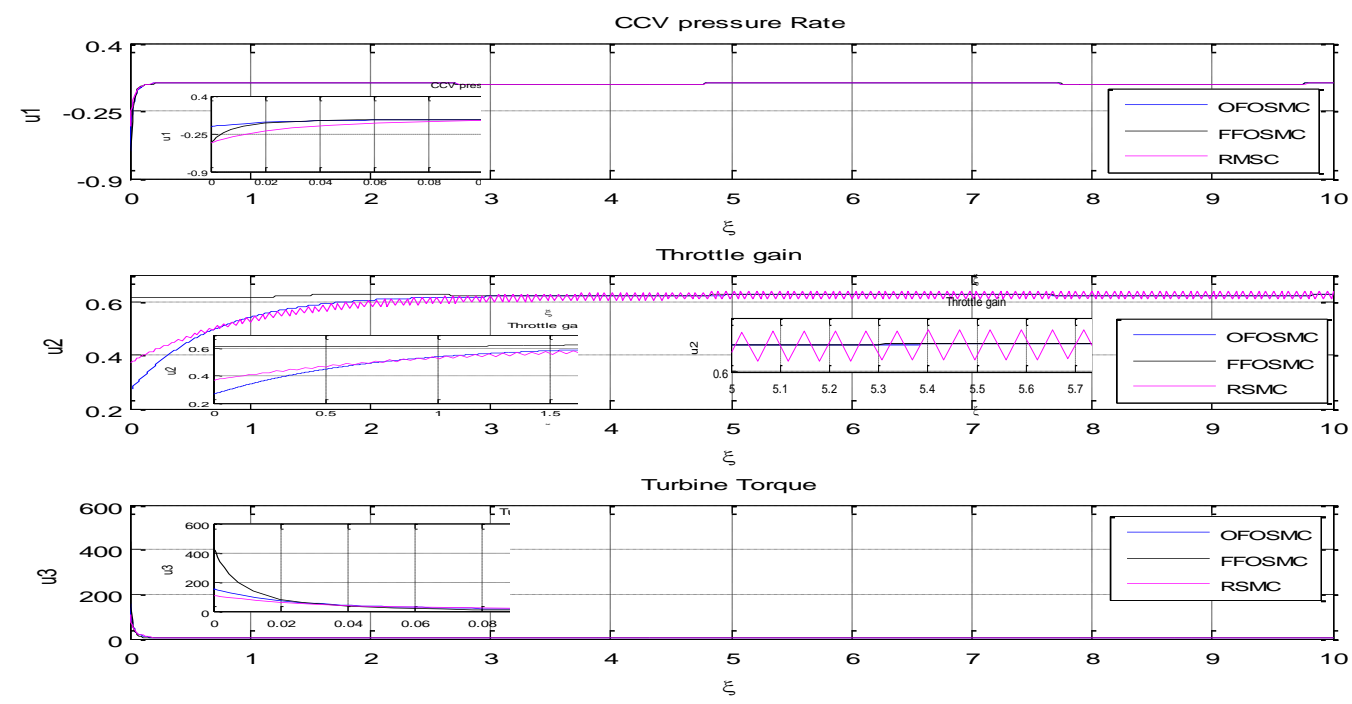

Fig. 8 Control efforts in Closed Loop

This Result shows the effectiveness of the proposed control law in surge and rotating stall control. 


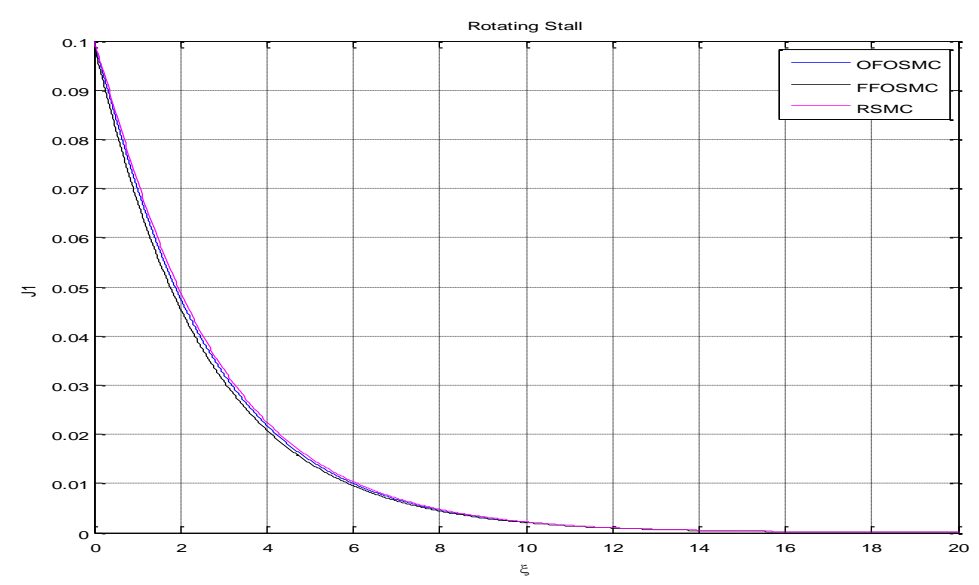

Fig. 9 Rotating Stall Harmonics

Fig.10 presents the optimization criterions for the time responses given in Fig.7. From Fig.7, it is seen that tracing criterion is improved by the OFOSMC and FFOSMC if compared with the RSMC case, while the best improvement is obtained with proposed FFOSMC. The control gain are also reduced. Also, it is seen that much more chattering is present in RSMC case than the FFOSMC and OFOSMC. Additionally, due to the fluctuations/chattering criterion, the OFOSMC used less control effort than FFOSMC.
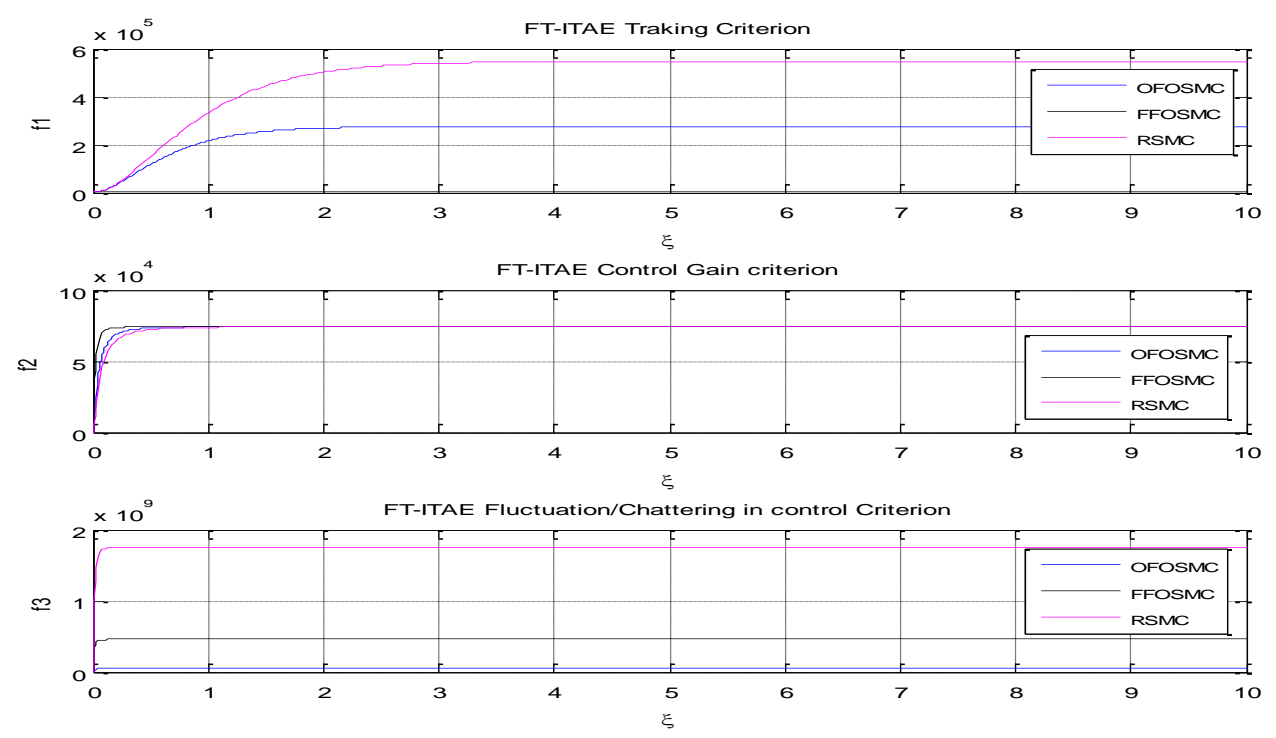

Fig. 10 Optimization criterions $\left(f_{1}, f_{2}, f_{3}\right)$

Figs. 11 and 12 show the Pareto graphical results produced by MOPSO. The true Pareto front of the problem is shown as an "o" points (250 points) and MOPSO results as"*" points (100 points). The graphical solutions show that the MOPSO is able to cover the entire Pareto front of the problem. This makes the value of this metric relevant, since the most solutions produced by the MOPSO are big part of the true Pareto front of the problem. 


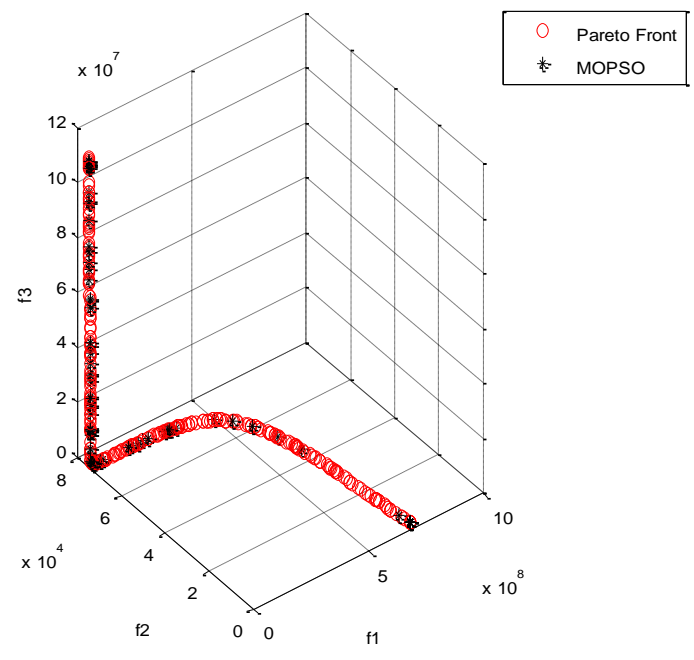

Fig. 11 Pareto fronts for OFOSMC

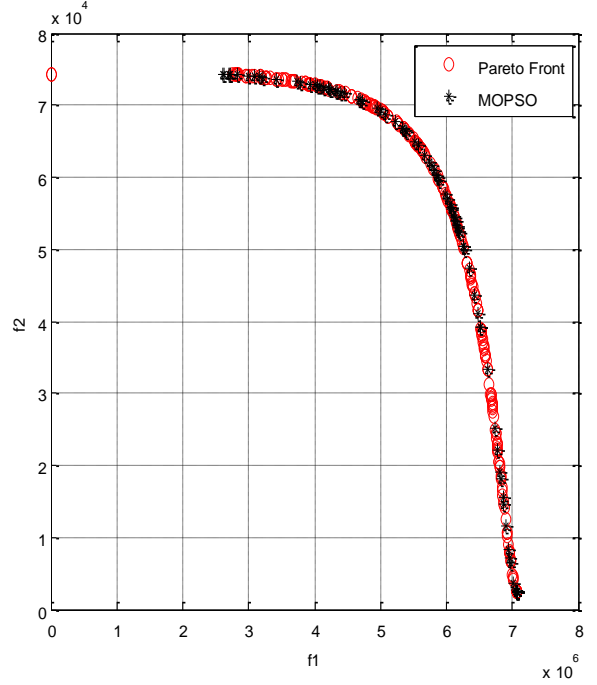

Fig. 12 Pareto fronts for FFOSMC

\section{CONCLUSION}

In this study, two optimized FOSMC has been designed for aerodynamic improvement in the gas turbine. The aim was to improve Surge /rotating stall of variable speed axial compressor (VSAC) without the need to prior knowledge of disturbances and uncertainties, and especially to attenuate the possible chattering and fluctuation in control signal if compared with the robust SMC design. We proposed an hybrid and intelligent control system that combines the advantages in terms of robustness of the fractional order and sliding mode control, the smoothness of the fuzzy approach, and the good convergence speed of multiobjective particle swarm approach (MOPSO). The control law of the two designed controllers FFOSMC and OFOSMC was composed of two steps. The First step is the design robust control law, and the second step is the optimization of this control. The parameters of the designed controllers have been obtained by using MOPSO strategy. The two proposed FFOSMC and OFOSMC provide better tracking and robustness capabilities than RSMC, which is only computationally simple.

The two proposed controllers also reduces chattering and fluctuation of actuators. These are even achieved by a smoother (fuzzy) and optimized control signal. Finally, the simulation results show that the two proposed control algorithms are an appropriate control for GravdahlEgeland Model with uncertainties and perturbations.

\section{REFERENCES}

[1] Gravdahl, J. T., Egeland, O. "Moore-Greitzer Axial Compressor Model with Spool Dynamics“, In $36^{\text {th }}$ IEEE Conference on Decision and Control. Part 1 (of 5), San Diego, CA, USA, pp. 4714 - 4719, 1997. DOI: 10.1109/CDC. 1997.649750.

[2] Gravdahl, J. T., Egeland, O. "Compressor surge and rotating stall Modelling and control", Advances in Industrial Control, Springer Verlag. London Limited, 1998. ISBN: 978-1-4471-0827-6 DOI: 10.1007/978-1-4471-0827-6 
[3] Sari, O., Akhrif, O., Saydy, L. "Qualitative Analysis of an Axial Compressor Model with Non-constant Speed“", In ASME 2011 Power Conference, Denver, Colorado, USA, 2011 (1), pp. 515 - 524, 2011. DOI: 10.1115/power2011-55172

[4] Sari, G., Akhrif, O., Saydy, L. "The impact of speed variation on the stability of variable speed axial compressors at efficient operating points“, In American Control Conference, Canada, pp. 404 - 410, 2012. DOI: 10.1109/acc.2012.6314785.

[5] Sari, G., "Model analysis and nonlinear control of air compressors", doctoral dissertation. Montreal University, Canada, 2014. Available at: https://publications .polymtl.ca/1532/ [Accessed: date (17/11/2021)]

[6] Sheng, H., Huang,W., Zhang, T., Huang, X. "Robust Adaptive Fuzzy Control of Compressor Surge Using Back-stepping“, Journal for science and engineering 2014 (39), pp. 9301 - 9308, 2014. DOI: 10.1007/s13369-014-1448-1

[7] Moghaddam, J. J., Madani, M. "A decoupled adaptive neuro-fuzzy sliding mode control system to control rotating stall and surge in axial compressors", Journal of Expert Systems with Applications 38 (4), pp. 4490 - 4496, 2011. DOI: 10.1016/j.eswa. 2010.09.122

[8] Zaiet, C., Akhrif, O., Saydy, L. "Modeling and Non Linear Control of a Gas Turbine“, In International Symposium on Industrial Electronics ISIE, pp. 2688 - 2694, 2006. DOI: $10.1109 /$ isie.2006.296037

[9] Debbah, A., Kherfane, H., Berkani, N. "Non-Linear robust control optimization to improving the aerodynamics in gas turbine“, Rev. Sci. Technol., Synthèse 25 (2), pp. 78 - 95, 2019. Available at: https://www.ajol.info/index.php/srst/article/view/192425

[10] Lin, S., Yang, C., Wu, P., Song, Z. "Fuzzy logic surge control in variable speed axial compressors", In $10^{\text {th }}$ IEEE International Conference on Control and Automation (ICCA), pp. 1178 - 1183, 2013. DOI: 10.1109/icca.2013.6565118

[11] Uddin, N., Gravdahl, J. T. "Active compressor surge control using piston actuation", In ASME 2011 Dynamic Systems and Control Conf. and Bath/ASME Symposium on Fluid Power and Motion Control, American Society of Mechanical Engineers, pp. 69 76, 2011. DOI: $10.1115 /$ dscc2011-6113

[12] Debbah, A., Kharfene, H. "GA/PSO robust sliding mode control of aerodynamics in gas turbine", Acta Universitatis Sapientiae Electrical and Mechanical Engineering 10(1), pp. 42 - 66, 2018. DOI: 10.2478/auseme-2018-0003

[13] Sheng, H. Huang,W., Zhang, T. "Output feedback control of surge and rotating stall in axial compressors", Asian Journal of Control 19 (2), pp. 1 - 7, 2017. DOI: 10.1002/asjc.1384

[14] Debbah, A., Kharfene, H., Karboua, A. "Using Robust sliding mode controller to improving the aerodynamic performance of a gas turbine“, In $4^{\text {th }}$ international Seminar on new and renewable energies, pp. 1 - 6, 2016. Available at: http://uraer. cder.dz /sienr /sienr2016/ne/ 7_Article_A_DEBBAH_C07

[15] Ghanavati, M., Salahshoor, K., Motlagh, M. R. J., Ramazani, A., Moarefianpour, A. “A novel combined approach for gas compressors surge suppression based on robust adaptive control and backstepping", Journal of Mechanical Science and Technology 32 (2), pp. 823 - 833, 2018. DOI: 10.1007/s12206-018-0133-1

[16] Bartolini, G., Muntoni, A., Pisano, A., Usai, E. "Compressor surge active control via throttle and CCV actuators: a second-order sliding-mode approach", In 10th IEEE 
International Workshop on Variable Structure Systems, pp. 274 - 279, 2008. DOI: 10.1109/vss.2008. 4570720

[16] Defoort, M., Floquet, T., Kokosy, A., Perruquetti, W. "A novel higher order sliding mode control scheme“, Systems and Control Letters 58 (2), pp. 102 - 108, 2009. DOI: 10.1016/j.sysconle.2008.09.004

[17] Ozer, H. O., Hacioglu, Y., Yagiz, N. "High order sliding mode control with estimation for vehicle active suspensions", Transactions of the Institute of Measurement and Control, pp.1 - 14, 2017. DOI: 10.1177/0142331216685394

[18] Kumar, J., Azar, A. T., Kumar, V., Rana, K. P. S. “Design of Fractional Order Fuzzy Sliding Mode Controller for Nonlinear Complex Systems“, Chapter 9, Advances in Nonlinear Dynamics and Chaos (ANDC), pp. 249 - 282, 2018. DOI: 10.1016 /b978-012-813592-1.00009-x

[19] Delavari, H., Ghaderi, R., Ranjbar, A., Momani, S. "Fuzzy fractional order sliding mode controller for nonlinear system", Communications in Nonlinear Science and Numerical Simulation 15 (4), pp. 963 - 978, 2010. DOI: 10.1016/j.cnsns. 2009. 05.025

[20] Du, W.J., Zhang, J.G., Qin, S. “ Hopf bifurcation and sliding mode control of chaotic vibrations in a four-dimensional hyper chaotic System“, IAENG International Journal of Applied Mathematics 46 (2), pp. 247 - 255, 2016. Available at: http://www.iaeng.org/ IJAM/issues_v46/issue_2/IJAM_46_2_15

[21] Lui, J. "Intelligent Control Design and MATLAB Simulation", $1^{\text {th }}$ ed, Springer Singapore, Tsinghua University Press. Beijing, 2018. ISBN:978-981-10-5263-7, https://doi.org/10.1007/ 978-981-10-5263-7

[22] Chen, D. Y., Liu, Y. X., Ma, X. Y., Zhang, R. F. "No-chattering sliding mode control in a class of fractional-order chaotic systems", Chinese Physics B 20 (12), 2011. DOI: $10.1088 / 1674-1056 / 20 / 12 / 120506$

[23] Yin, C., Chen, Y., Zhong, S. "Fractional-order sliding mode based extremum seeking control of a class of nonlinear systems“", Automatica Elseiver 50 (12), pp. 3173 - 3181, 2014. DOI: $10.1016 /$ j.automatica. 2014.10

[24] Duc, T. M., Van Hoa, N., Dao, T. P. “Adaptive Fuzzy Fractional-Order Nonsingular Terminal Sliding Mode Control for a Class of Second-Order Nonlinear Systems“, Journal of Computational and Nonlinear Dynamics ASME 13 (3), pp. 1 - 8, 2018. DOI: $10.1115 / 1.4038642$

[25] Monje, C. A., Chen, Y. Q., Vinagre, B. M., Xue, D., Feliu, V. "Fractional-order Systems and Controls: Fundamentals and Applications“, Springer-Verlag London Limited, 2010. ISBN:978-1-84996-335-0, DOI: 10.1007/978-1-84996-335-0

[26] Likaj, R., L., Shala, A. "Optimisation and control of vehicle suspension using linear quadratic gaussian control", Strojnícky časopis - Journal of Mechanical Engineering 68 (1), pp. 61 - 68, 2018, DOI: 10.2478/scjme-2018-0006

[27] Elesztos, P., Jančo, R., Voštiar, V. "Optimization of welding process using a genetic algorithm“, Strojnícky časopis - Journal of Mechanical Engineering 68 (2), pp. 17 - 24, 2018. DOI: $10.2478 /$ scjme-2018-0014

[28] Yanzhi, R., Sanyang, L. "Modified particle swarm optimization algorithm for engineering structural optimization problem“, In $13^{\text {th }}$ International Conference on Computational Intelligence and Security, pp. 504 - 507, 2017. DOI: 10.1109/ cis. 2017.00117 
[29] Coello, C. A. C., Pulido, G. T., Lechuga, M. S. "Handling multiple objectives with particle swarm optimization", IEEE Transactions on Evolution 8 (3), pp. 256 - 279, 2004. DOI: $10.1109 /$ tevc. 2004.826067

[30] Lin, Q., Liu, S., Zhu, Q., Tang, C., Song, R., Chen, J., Zhang, J. "Particle Swarm Optimization With a Balanceable Fitness Estimation for Many-Objective Optimization Problems“, IEEE Transactions on Evolutionary Computation 22(1), pp. 32 - 46, 2018. DOI: $10.1109 /$ tevc.2016.2631279

[31] Juneja, M., Nagar, S. K. "Particle swarm optimization algorithm and its parameters: A review", In International Conference on Control, Computing, Communication and Materials, pp. 1 - 5, 2016. DOI: 10.1109/iccccm.2016.7918233

[32] Khadar, B.,Jagannadha, R. Murahari, K. "Multi-objective optimization of process parameters for powder mixed electrical discharge machining of Inconel X-750 alloy using Taguchi-Topsis approach“, Strojnícky časopis - Journal of mechanical engineering 71(1), pp. 1 - 18, 2021. DOI: 10.2478/scjme-2021-0001

[33] Liu, J., Zhang, H., He, K., Jiang, S. "Multi-objective particle swarm optimization algorithm based on objective space division for the unequal-area facility layout problem“, Expert Systems with Applications 102, pp. 179 - 192, 2018. DOI: 10.1016/j.eswa. 2018.02 .035

[34] Zhang, H., Yue, D., Xie, X., Hu, S., Weng, S. "Pareto-dominance based adaptive multiobjective optimization for hydrothermal coordinated scheduling with environmental emission“, Applied Soft Computing 69, pp. $270-287$, 2018. DOI: 10.1016/j.asoc.2018.04.058 